\title{
Hippocampal atrophy and EEG markers in subjects with mild cognitive impairment
}

\author{
D.V. Moretti ${ }^{\text {a,* }}$, C. Miniussi ${ }^{\text {a,b }}$, G.B. Frisoni ${ }^{\text {a }}$, C. Geroldi ${ }^{a}$, O. Zanetti ${ }^{\text {a }}$, \\ G. Binetti a , P.M. Rossini a,c,d \\ a IRCCS 'S. Giovanni di Dio - FBF, 4, Pilastroni Road, 25125 Brescia, Italy \\ ${ }^{\mathrm{b}}$ Department of Biomedical Sciences and Biotechnologies, University of Brescia, Italy \\ ${ }^{c}$ AFaR, Department of Neuroscience, 'S. Giovanni Calibita - Fatebenefratelli', Rome, Italy \\ ${ }^{\mathrm{d}}$ Neurology Clinic, University 'Campus Biomedico', Rome, Italy
}

Accepted 7 September 2007

Available online 30 October 2007

\begin{abstract}
Objective: The present study evaluates the potential relationship between hippocampal atrophy and EEG brain rhythmicity, as assessed by relative band power and alpha frequency indices in a cohort of subjects with mild cognitive impairment (MCI).

Methods: Eighty-eight subjects falling within the definition of MCI patients were enrolled. All subjects underwent EEG recording and magnetic resonance imaging (MRI). Volumetric morphometry estimates of the hippocampal region were computed. Individual EEG frequencies were indexed by the theta/alpha transition frequency (TF) and the individual alpha frequency (IAF). The relative power was separately computed for delta, theta, alpha1, alpha2 and alpha3 frequency bands. The MCI cohort was classified into four subgroups, based on the mean and standard deviations of the hippocampal volume of a normal elderly control sample.

Results: The group with moderate hippocampal atrophy showed the highest increase in the theta power on frontal regions, and of the alpha 2 and alpha3 powers on frontal and temporo-parietal areas. The analysis of the individual alpha frequency markers showed that the values for the alpha markers were highest in the group with the smallest hippocampal volume, whereas in the group with moderate hippocampal atrophy, these values were lower than in the group with severe atrophy.

Conclusions: The relationship between hippocampal atrophy and EEG activity changes in MCI subjects is not proportional to the hippocampal atrophy. Therefore, EEG markers could represent a new tool for differential diagnosis.

Significance: The hippocampal atrophy induces different brain synchronization/desynchronization patterns. EEG changes model the brain activity induced by a discrete change of the hippocampal volume. The changes in the EEG rhythmicity differ greatly from those in MCI patients with subcortical vascular damage.

(C) 2007 International Federation of Clinical Neurophysiology. Published by Elsevier Ireland Ltd. All rights reserved.
\end{abstract}

Keywords: MCI; Hippocampal atrophy; EEG; Alpha rhythm; Theta rhythm; MRI; Volume-based morphometry

\section{Introduction}

Mild cognitive impairment (MCI) is a clinical status intermediate between elderly normal cognition and dementia. This status affects a significant part of the elderly population, and is characterized by memory complaints and cognitive impairment, but not by dementia, on neuropsy-

\footnotetext{
${ }^{*}$ Corresponding author. Tel.: +39 0303501595; fax: +39 0303533513.

E-mail address: davide.moretti@afar.it (D.V. Moretti).
}

chological testing (Flicker et al., 1991; Petersen et al., 1995, 2001). Within this borderline condition, scientific and health organization interests rely on the demonstration of a steep rise in the annual conversion rate from MCI to dementia; such rise is 3-6 times higher than that observed in normal aging (Petersen et al., 1997, 2000, 2001; Gauthier et al., 2006; Fischer et al., 2007). This syndrome can be divided into amnestic and non-amnestic MCI subgroups, according to whether or not the subject has memory impairment. Both subtypes can further be classified as 
single or multiple domains, based on the number of cognitive domains affected (Hamalainen et al., 2006; Gauthier et al., 2006). Nevertheless, MCI remains a clinically and pathologically heterogeneous condition in need of more extensive definition and classification (Wahlund et al., 2003). The hippocampus is one of the first and most affected brain regions impacted by both Alzheimer's disease and MCI (Arnold et al., 1991; Bobinski et al., 1995; Price and Morris, 1999; Schonheit et al., 2004; Bennett et al., 2004; Pennanen et al., 2005; Tapiola et al., 2006). In mild-to-moderate Alzheimer's disease patients, it has been shown that hippocampal volumes are $27 \%$ smaller than in normal elderly controls (Callen et al., 2001; Du et al., 2001), whereas patients with MCI show a volume reduction of $11 \%$ (Du et al., 2001; Apostolova et al., 2006). So far, from a neuropathological point of view, the progression of disease from early or very early MCI to later stages seems to follow a linear course (Frisoni et al., 2002). Nevertheless, there is some evidence from functional (Gold et al., 2000; Della Maggiore et al., 2002; Hamalainen et al., 2006) and biochemical studies (Lavenex and Amaral, 2000) that the process of conversion from non-demented to clinically evident demented state is not so linear. Recent fMRI studies have suggested increased medial temporal lobe (MTL) activations in MCI subjects versus controls, during the performance of memory tasks (Dickerson et al., 2004, 2005). Nonetheless, fMRI findings in MCI are discrepant, as MTL hypoactivation similar to that seen in AD patients (Pariente et al., 2005) has also been reported (Machulda et al., 2003). Recent postmortem data from subjects - who had been prospectively followed and clinically characterized up to immediately before their death - indicate that hippocampal choline acetyltransferase levels are reduced in Alzheimer's dementia, but in fact they are upregulated in MCI (Lavenex and Amaral, 2000; DeKosky et al., 2002), presumably because of reactive upregulations of the enzyme activity in the unaffected hippocampal cholinergic axons. Previous EEG studies (Babiloni et al., 2000; Jelic et al., 2000, 1996; Ferreri et al., 2003) have shown a decrease - ranging from 8 to $10.5 \mathrm{~Hz}$ (low alpha) - of the alpha frequency power band in MCI subjects, when compared to normal elderly controls (Zappoli et al., 1995; Huang et al., 2000; Jelic et al., 2000; Koenig et al., 2005; Babiloni et al., 2006a). However, a recent study has shown an increase - ranging from 10.5 to $13 \mathrm{~Hz}$ (high alpha) - of the alpha frequency power band, on the occipital region in MCI subjects, when compared to normal elderly and AD patients (Babiloni et al., 2006a). These somewhat contradictory findings may be explained by the possibility that MCI subjects have different patterns of plastic organization during the disease, and that the activation (or hypoactivation) of different cerebral areas is based on various degrees of hippocampal atrophy. If this hypothesis is true, then EEG changes of rhythmicity have to occur non-proportionally to the hippocampal atrophy, as previously demonstrated in a study of auditory evoked potentials (Golob et al., 2007). Moreover, this pattern has to be different from subcortical vascular MCI (Moretti et al., 2007), as well as potentially helpful in differential diagnosis. In the present study, we tested this hypothesis through the EEG frequency analysis. The quantitative analysis of electroencephalographic (EEG) rhythms in resting subjects (Destexhe and Sejnowski, 1996; Suffczynski et al., 2001; Elul, 1972; Lopes da Silva et al., 1976, 1980; Steriade and Llinas, 1988; Singer, 1993; Klimesch, 1999; Pfurtscheller and Lopes da Silva, 1999; Nunez et al., 2001; Suffczynski et al., 2001; Babiloni et al., 2006b; Prichep et al., 2006; Rossini et al., 2006; Klimesch et al., 2007) is a low-cost but still powerful approach to the study of elderly subjects in normal aging, MCI and dementia (Gueguen et al., 1991; Maurer and Dierks, 1992; Leuchter et al., 1993; Schreiter-Gasser et al., 1993; Jelic et al., 1996; Babiloni et al., 2000; Bennys et al., 2001; Moretti et al., 2004; Rossini et al., 2006). In this study, the relationship between EEG rhythmicity and hippocampal atrophy was assessed in a population of MCI subjects matched for cognitive decline and cerebrovascular damage (CVD). Within-region differences, as computed at full-scalp region level, and two individual macroregions, namely frontal and temporo-parietal ones, and the between-region changes of EEG rhythmicity were also considered in the analysis. The results confirm the hypothesis that the relationship between hippocampal volume and EEG rhythmicity is not proportional to the hippocampal atrophy, as revealed by the analyses of both the relative band powers and the individual alpha markers. In our analysis, such a pattern seems to emerge because, rather than a classification based on clinical parameters, discrete hippocampal volume differences (about $1 \mathrm{~cm}^{3}$ ) are analyzed. Moreover, changes in EEG rhythmicity are very different from those in subcortical vascular MCI.

\section{Materials and methods}

\subsection{Subjects}

Eighty-eight subjects with MCI were recruited in this study. All experimental protocols had previously been approved by the local Ethics Committee. Written informed consent was obtained from all study participants or their caregivers, according to the Code of Ethics of the World Medical Association (Declaration of Helsinki).

\subsection{Diagnostic criteria}

Patients were taken from a prospective project on the natural history of MCI. The project was aimed to study the natural history of non-demented persons with apparently primary cognitive deficits, i.e., deficits not due to psychic (anxiety, depression, etc.) or physical (hypothyroidism, vit B12 and folate deficiency, uncontrolled heart disease, uncontrolled diabetes, etc.) conditions. Patients were rated with a series of standardized diagnostic and severity instruments, including the Mini-Mental State Examination (MMSE; 
Folstein et al., 1975), the Clinical Dementia Rating Scale (CDRS; Hughes et al., 1982), the Hachinski Ischemic Scale (HIS; Rosen et al., 1980), the Instrumental and Basic Activities of Daily Living (IADL, BADL, Lawton and Brodie, 1969) and the Age-Related White Matter Changes Scale (Wahlund et al., 2001). In addition, patients underwent diagnostic neuroimaging procedures (magnetic resonance imaging, MRI), and laboratory testing to rule out other causes of cognitive impairment. These inclusion and exclusion criteria for MCI were based on previous seminal studies (Albert et al., 1991; Devanand et al., 1997; Flicker et al., 1991; Petersen et al., 1995, 1997, 2001; Portet et al., 2006; Geroldi et al., 2006). Inclusion criteria of the study were all of the following: (i) complaint by the patient, or report by a relative or the general practitioner, of memory or other cognitive disturbances; (ii) Mini-Mental State Examination (MMSE) score of 24 27/30, or MMSE of 28 and higher plus low performance (score of 2-6 or higher) on the clock drawing test (Shulman, 2000); (iii) sparing of instrumental and basic activities of daily living or functional impairment steadily due to causes other than cognitive impairment, such as physical impairments, sensory loss, gait or balance disturbances, etc. Exclusion criteria were any one of the following: (i) patients aged 90 years and older; (ii) history of depression or juvenile-onset psychosis; (iii) history or neurological signs of major stroke; (iv) other psychiatric diseases, epilepsy, drug addiction, alcohol dependence; (v) use of psychoactive drugs, including acetylcholinesterase inhibitors or other drugs enhancing brain cognitive functions; and (vi) current or previous uncontrolled or complicated systemic diseases (including diabetes mellitus), or traumatic brain injuries. All patients underwent: (i) semi-structured interview with the patient and whenever possible - with another informant (usually, the patient's spouse or a child of the patient) by a geriatrician or neurologist; (ii) physical and neurological examinations; (iii) performance-based tests of physical function, gait and balance; (iv) neuropsychological battery assessing verbal and non-verbal memory, attention and executive functions (Trail Making Test B-A; Clock Drawing Test; Amodio et al., 2002; Shulman, 2000), abstract thinking (Raven matrices; Basso et al., 1987), frontal functions (Inverted Motor Learning; Spinnler and Tognoni, 1987); language (Phonological and Semantic fluency; Token test; Carlesimo et al., 1996; Novelli et al., 1986), and apraxia and visuo-constructional abilities (Rey figure copy; Caffarra et al., 2002); (v) assessment of depressive symptoms by means of the Center for Epidemiologic Studies Depression Scale (CES-D; Radloff, 1977).

\subsection{EEG recordings}

All recordings were obtained in the morning hours with subjects resting comfortably. Vigilance was continuously monitored in order to avoid drowsiness. The EEG activity was recorded continuously from 19 sites, by using electrodes set in an elastic cap (Electro-Cap International, Inc.) and positioned according to the 10-20 International system (Fp1, Fp2, F7, F3, Fz, F4, F8, T3, C3, Cz, C4, T4, T5, P3, Pz, P4, T6, O1, O2). The ground electrode was placed in front of $\mathrm{Fz}$. The left and right mastoid served as reference for all electrodes. The recordings were used offline to re-reference the scalp recordings to common average. Data were recorded with a band-pass filter of $0.3-70 \mathrm{~Hz}$, and digitized at a sampling rate of $250 \mathrm{~Hz}$ (BrainAmp, BrainProducts, Germany). Electrodes-skin impedance was set below $5 \mathrm{k} \Omega$. Horizontal and vertical eye movements were detected by recording the electrooculogram (EOG). The recording was performed in subjects with closed eyes and lasted $5 \mathrm{~min}$. Longer recordings would have reduced the variability of data; however, they would also have increased the possibility of slowing of EEG oscillations, due to reduced vigilance and/or arousal fluctuations. EEG data were analyzed and fragmented off-line in consecutive epochs of $2 \mathrm{~s}$ with a frequency resolution of $0.5 \mathrm{~Hz}$. The average number of epochs analyzed was 140 , and ranged from about 130 to 150 . The EEG epochs with ocular, muscular and other types of artifacts were discarded.

\subsection{Analysis of individual frequency bands}

A digital FFT-based power spectrum analysis (Welch technique, Hanning windowing function, no phase shift) computed the power density of EEG rhythms with $0.5 \mathrm{~Hz}$ frequency resolution (range, $2-40 \mathrm{~Hz}$ ). Two anchor frequencies were selected according to literature guidelines (Klimesch, 1999), that is, the theta/alpha transition frequency (TF) and the individual alpha frequency (IAF) peak. The TF marks the transition frequency between theta and alpha bands, and represents an estimate of the frequency at which the theta and alpha spectra intersect. We computed the TF as the minimum power in the alpha frequency range, since our EEG recordings were performed at rest. The IAF represents instead the frequency with the maximum power peak within the extended alpha range $(5-14 \mathrm{~Hz})$. TF and IAF could be clearly identified in 88 MCI subjects whose EEG data were then statistically analyzed. Based on TF and IAF, we estimated the frequency band range for each subject, as follows: delta from TF-4 to TF-2, theta from TF-2 to TF, low alpha band (alpha1 and alpha2) from TF to IAF, and high alpha band (or alpha3) from IAF to IAF +2 . The alpha1 and alpha2 bands were computed for each subject, as follows: alpha1 from TF to the middle point of the TF-IAF range, and alpha2 from such middle point to the IAF peak (Moretti et al., 2004). Finally, we computed the relative power spectra for each subject, in the frequency bands so determined. The relative power density was computed for each frequency band as the ratio between the absolute and the mean power spectra from 2 to $40 \mathrm{~Hz}$. The relative band power of each band was defined as the mean of the relative band power for each frequency bins within that band. In order to disclose cortical regional differences, we computed IAF, TF and relative power spectra on frontal and temp- 
oro-parietal regions. Fp1, Fp2, F7, F3, Fz, F4, F8 were pooled for the frontal region; T3, T4, T5, P3, Pz, P4, T6 were pooled for the temporo-parietal area. We carried out the same procedure as for measuring the full scalp to evaluate alpha indices and relative power spectra for each of the two individual cortical macroregions.

\subsection{Magnetic resonance imaging (MRI) and hippocampal atrophy evaluation}

For each subject, a high-resolution sagittal T1 weighted volumetric MR scan was acquired at the Neuroradiology Unit of the 'Città di Brescia' Hospital, Brescia, by using a 1.0 T Philips Gyroscan scanner, with a gradient echo 3D technique: $\mathrm{TR}=20 \mathrm{~ms}, \mathrm{TE}=5 \mathrm{~ms}$, flip angle $=30^{\circ}$, field of view $=220 \mathrm{~mm}$, acquisition matrix $256 \times 256$, slice thickness $1.3 \mathrm{~mm}$. 3D images were processed through a software developed at the McConnel Brain Imaging Centre (Montreal Neurological Institute, McGill University, Montreal, Canada). The processing pipeline included: magnetic field non-uniformity correction, intensity normalization and brain-to-brain linear registration to a standard template in the stereotaxic space (ICBM152) based on the Talairach atlas (Collins et al., 1994). Each registered image was visually compared to the ICBM152 template using the software program REGISTER (McGill University, Montreal, Canada) and, when the automatic registration failed (mainly due to high scalp brightness), a manual registration was performed, based on 11 anatomical landmark points, distributed over the cerebrum and the brainstem (i.e., the most anterior point of the temporal poles, the most posterior aspect on the occipital lobe, the most anterior point on the frontal lobe, the central sulcus, the inferior ventral aspect of the pons-midbrain cleft, the genu and the splenium of the corpus callosum, the interthalamus adhesion and the eyes).

The hippocampi were manually traced by a single tracer with the software program DISPLAY (McGill University, Montreal, Canada) on contiguous coronal 1.5 -mm thick images. The anatomical starting point was the hippocampal head when it first appears below the amygdala, the alveus defining the superior and anterior border of the hippocampus. The fimbria was included in the hippocampal body, while the gray matter rostral to the fimbria was excluded. The hippocampal tail was traced until it was visible as an oval shape located caudally and medially to the trigone of the lateral ventricles (Pruessner et al., 2000). The intraclass correlation coefficient for intrarater reliability was 0.95 . To obtain the native hippocampal volume, the brain with the traced region-of-interest was back-transformed from the stereotaxic to the native space. The total intracranial volume (TIV) was computed by manually tracing the entire intracranial cavity (the lower boundary being the foramen magnum) on 7-mm thick coronal slices, by the use of the software DISPLAY. Native hippocampal volumes were normalized to the TIV and rescaled to the mean total intracranial volume, according to the following for- mula: [hippocampal volume/TIV] $\times$ grand mean TIV/ 1000. Left and right hippocampal volumes were pooled to obtain a single value for the hippocampal atrophy.

In order to focus atrophy-induced changes, subjects were subdivided into four groups based on the hippocampal volume of a normal control sample matched with the whole MCI group for age, sex and education. In the normal group the ratio female/male was $93 / 46$, the mean age was $68.9(\mathrm{SD} \pm 10.3)$, and the mean education was 8.9 years $(\mathrm{SD} \pm 9.4)$. In the whole $\mathrm{MCI}$ group the ratio female/male was $63 / 25$, the mean age was 69.5 $(\mathrm{SD} \pm 8.1)$, and the mean education was 7.6 years $(\mathrm{SD} \pm 4.1)$. The mean and standard deviations of the hippocampal volume, in the normal elderly population of 139 subjects, were $5.72 \pm 1.1 \mathrm{~cm}^{3}$. Therefore, four groups were obtained: the 'no-atrophy group', with hippocampal volume equal or higher than the normal mean (total hippocampal volume, from 6.79 to $5.75 \mathrm{~cm}^{3}$; G1); the 'mild-atrophy group', with hippocampal volume within $1.5 \mathrm{SD}$ below the mean value for the normal control (total hippocampal volume, from 5.70 to $4.70 \mathrm{~cm}^{3}$; G2); the 'moderate-atrophy group', with hippocampal volume between 1.5 and $3 \mathrm{SD}$ below the mean value for the normal hippocampus (total hippocampal volume, from 4.65 to $3.5 \mathrm{~cm}^{3}$; G3); and the 'severe-atrophy group', with hippocampal volume between 3 and 4.5 SD below the mean of the hippocampal volume values for the normal control (total hippocampal volume, from 3.4 to $\left.2.53 \mathrm{~cm}^{3} ; \mathrm{G} 4\right)$. The rationale for the selection of $1.5 \mathrm{SD}$ was to obtain enough pathological groups based on hippocampal volume. A SD below 1.5 could still include a 'normal' population with respect to hippocampal volume. On the other hand, a SD above 1.5 could not allow an adequate size of all study subgroups. Table 1 shows the mean demographic and clinical values for the study groups. Women were overrepresented almost in each group. Since no gender-specific differences in EEG rhythms are known, we assumed that this would not interfere with our results.

\subsection{Statistical analysis}

In order to avoid confounding effects, each statistical analysis of variance (ANOVA) was carried out by using age, education, gender, MMSE score, Age-Related White Matter Changes Scale score and cranial size as covariates. Duncan's test was used for post hoc comparisons. For all statistical tests, the significance was set to $p<0.05$.

First, 3 two-way statistical analyses of variance (ANOVA) of EEG relative power data were performed, by using the factors of Groups (G1, G2, G3, G4) as independent variables, and the frequency band (delta, theta, alpha1, alpha2, alpha3) as dependent variable. We performed a Box- $M$ test for violations of ANOVA assumptions, for multiple dependent variables and covariates. The test was not significant ( $p=0.45$ ); this possibly being indicative of poor statistical power of the analysis, we performed subsidiary ANOVAs with subgroups matched for age, education, gender and MMSE for each of the 3 two- 
Table 1

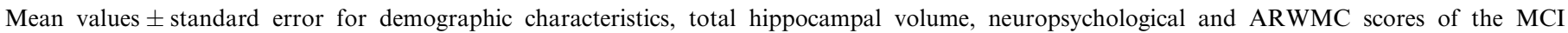
subgroups, based on mean and standard deviations in a normal elderly sample

\begin{tabular}{|c|c|c|c|c|}
\hline & Group 1 & Group 2 & Group 3 & Group 4 \\
\hline Subjects (F/M) & $14(10 / 4)$ & $41(33 / 8)$ & $21(12 / 9)$ & $12(8 / 4)$ \\
\hline Age & $66.8( \pm 0.5)$ & $67.4( \pm 0.2)$ & $70.9( \pm 0.5)$ & $75.8( \pm 1.0)$ \\
\hline Education & $9.8( \pm 0.5)$ & $6.8( \pm 0.07)$ & $6.9( \pm 0.1)$ & $9.4( \pm 0.3)$ \\
\hline MMSE & $27( \pm 0.1)$ & $27.2( \pm 0.04)$ & $26.8( \pm 0.1)$ & $25.4( \pm 0.3)$ \\
\hline Tot hipp volume & $6.1( \pm 0.02)$ & $5.3( \pm 0.007)$ & $4.4( \pm 0.04)$ & $3.4( \pm 0.08)$ \\
\hline ARWMC score & $4.3( \pm 0.3)$ & $4.4( \pm 0.09)$ & $2.2( \pm 0.16)$ & $3.9( \pm 0.2)$ \\
\hline
\end{tabular}

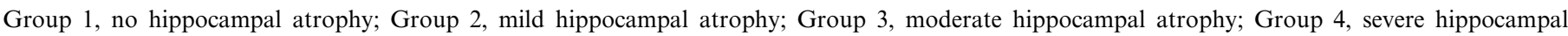
atrophy. F/M, female/male. Age and education are expressed in years. Hippocampal volume is expressed in $\mathrm{cm}^{3}$.

way analyses. The subjects were recruited from each previous group, without changing the selection criteria with respect to the hippocampal volume. The number of subjects in each group was the same as within the smallest subgroup in the main analysis ( $\mathrm{G} 4,12$ subjects).

Any significant difference among groups in demographic variables, age, education, gender and MMSE score as well as in CVD, as evaluated by the Age-Related White Matter Changes Scale (Wahlund et al., 2001), was preliminarly detected. Education and age showed significant differences among groups $(p<0.03)$. On the contrary, gender, MMSE score and CVD score did not show any significant difference. As successive step, two ANOVAs were performed for frontal and temporo-parietal regions, respectively, to evaluate the presence of cortical regional differences.

Furthermore, in order to assess the presence of EEG indices that correlate specifically with the hippocampal atrophy, statistical analyses were performed to evaluate the specificity of the alpha1/alpha3 ratio on full scalp, frontal and temporo-parietal regions, by using also the IAF of each considered region as a covariate. The alpha1/alpha3 ratio was chosen because of the different behaviour of low alpha and high alpha bands, based on hippocampal volume.

Subsequently, we checked the possibility that there were no differences between the two single-region analysis or, on the contrary, this comparison could reveal significant issues. To this aim, a three-way ANOVA was performed with groups as independent variable, and both EEG relative powers (delta, theta, alpha1, alpha2, alpha3) and regions (frontal and temporo-parietal) as dependent variable.

Finally, a three-way ANOVA was performed to compare alpha frequency markers (pooled IAF and TF), in order to reveal a possible between-region effect of the hippocampal atrophy on the alpha frequency. This ANOVA was carried out with the Group factors (G1, G2, G3, G4) as independent variables, and the pooled value for IAF and $\mathrm{TF}$ on frontal and temporo-parietal regions as dependent variables.

\section{Results}

Fig. 1 displays the results of the ANOVA analysis performed on the full-scalp region. These results show a signif- icant interaction between Group and Band power $[F(12,336)=2.36 ; p<0.007]$. Duncan's post hoc analysis showed that the G3 group had the highest alpha2 and alpha3 powers with statistical significance versus all the other groups ( $p<0.05 ; p<0.006$, respectively). The same trend was observed in the subsidiary ANOVA. These results show that the relationship between hippocampal atrophy and EEG relative powers is not proportional to the hippocampal atrophy, and highlight that the group with moderate hippocampal volume had a particular EEG activity pattern, in comparison with all the other groups.

Thus, the possibility that this particular EEG pattern might derive from a different expression of the EEG rhythmicity in different cortical areas was tested. Frontal and temporo-parietal areas were chosen because these regions have the richest connections with the hippocampal formation. Fig. 2 displays the results of the ANOVA analysis of the frontal region. These results show a significant interaction between Group and Band power $[F(12,336)=1.88)$; $p<0.04]$. Duncan's post hoc test showed that the G3 group, as well as the G1 group, had the highest alpha2 and alpha3 powers, with statistical significance with respect

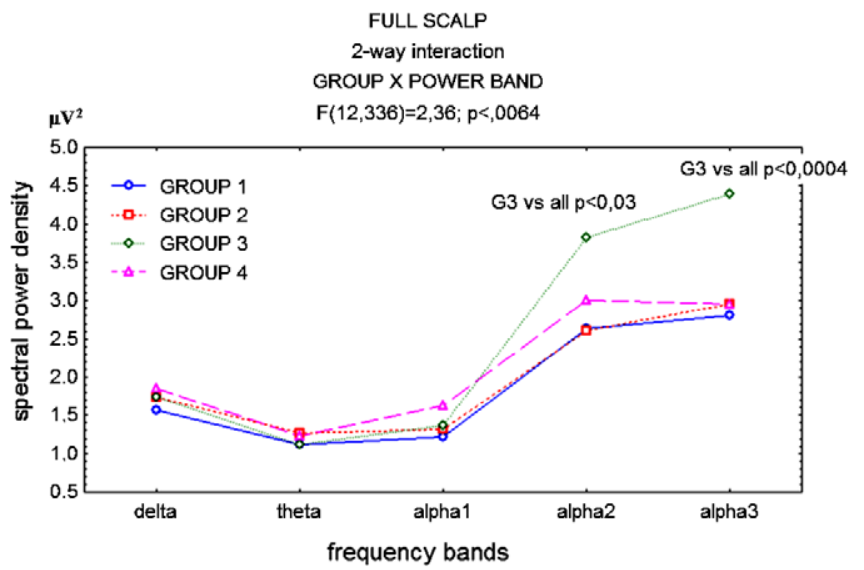

Fig. 1. Statistical ANOVA interaction among Group factors, and relative band powers (delta, theta, alpha1, alpha2, alpha3), on the full-scalp region. The groups are based on mean and standard deviations in a normal elderly sample. Group 1, no hippocampal atrophy; Group 2, mild hippocampal atrophy; Group 3, moderate hippocampal atrophy; Group 4 severe hippocampal atrophy. Post hoc results are indicated in the diagram. 


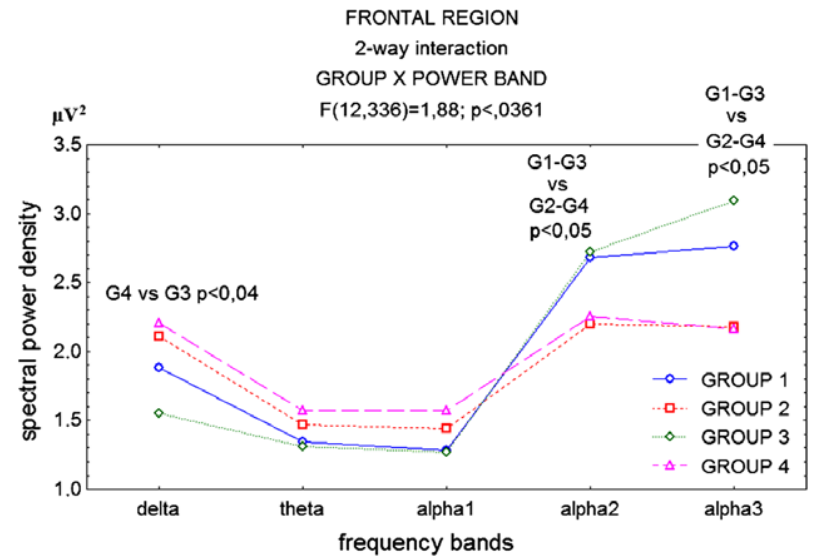

Fig. 2. Statistical ANOVA interaction among Group factors, and relative band powers (delta, theta, alpha1, alpha2, alpha3), on the frontal region. The groups are based on mean and standard deviations in a normal elderly sample. Group 1, no hippocampal atrophy; Group 2, mild hippocampal atrophy; Group 3, moderate hippocampal atrophy; Group 4 severe hippocampal atrophy. Post hoc results are indicated in the diagram.

to $\mathrm{G} 2$ and $\mathrm{G} 4(p<0.05)$. Moreover, the delta frequency showed a trend towards a decrease in the G3 group. Such decrease had the lowest value of all the other groups, and therefore became significant with respect to the G4 group $(p<0.04)$. The same trend was observed in the subsidiary ANOVA. Fig. 3 displays the ANOVA analysis of the temporo-parietal region. The results show a significant interaction between Group and Band power $[F(12,336)=3.41)$; $p<0.001]$. Duncan's post hoc test showed that the G3 group had the highest alpha2 and alpha3 powers, with respect to all the other groups ( $p<0.05 ; p<0.0005$, respectively). The same trend was observed in the subsidiary ANOVA.

Table 2 displays the values for the alpha1/alpha3 power ratio on full scalp, frontal and temporo-parietal regions.

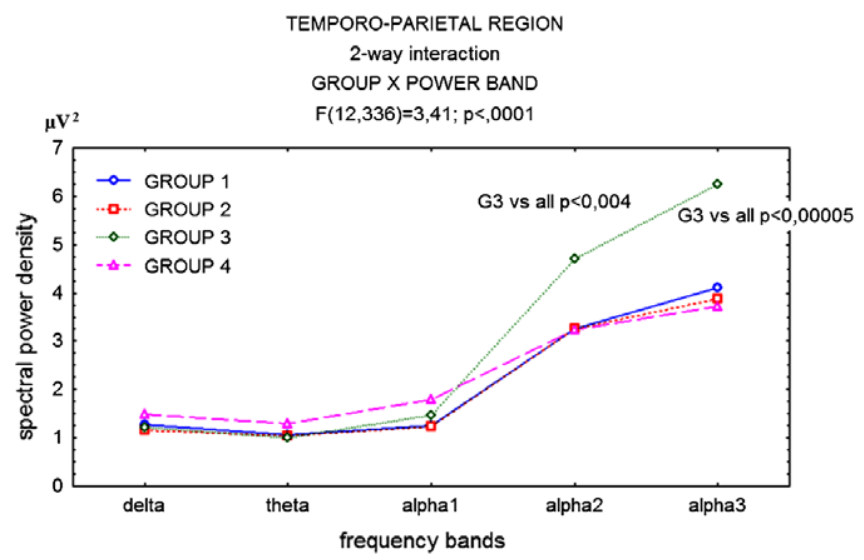

Fig. 3. Statistical ANOVA interaction among Group factors, and relative band powers (delta, theta, alpha1, alpha2, alpha3), on the temporoparietal region. The groups are based on mean and standard deviations in a normal elderly sample. Group 1, no hippocampal atrophy; Group 2, mild hippocampal atrophy; Group 3, moderate hippocampal atrophy; Group 4, severe hippocampal atrophy. Post hoc results are indicated in the diagram.
The statistical analysis of the alpha1/alpha3 power ratio showed a main effect of group $[F(3,79)=3.12 ; p<0.04]$ only on the frontal regions. Duncan's post hoc testing showed a significant increase in the ratio between $\mathrm{G} 4$ and G1 $(p<0.005)$, and G4 and G3 $(p<0.001)$. On full scalp and temporo-parietal regions, no statistical significance in the main effect of group ( $p=0.4 ; p=0.15$, respectively) was found.

As a last step of the analysis of the EEG relative powers, the between-region difference was tested, by comparing the frontal and the temporo-parietal regions. Fig. 4 displays the between-region ANOVA analysis. The results show a significant interaction 'Group $\times$ Band Power $\times$ Regions' $[F(12,336)=15.63) ; p<0.000]$. Duncan's post hoc test showed that the G3 group had the highest alpha2 powers with respect to the G2 group and the G4 group, on the frontal region $(p<0.0001)$ - as well as on the temporoparietal region $(p<0.0004)$, with respect to all the other groups. Moreover, the G3 group showed the highest alpha3 power with respect to all the other groups on frontal and temporo-parietal regions $(p<0.0004 ; p<0.0002$, respectively). Finally, the G4 group showed the highest delta power with respect to all the other groups on frontal regions. These results confirm the single-region analyses. We checked whether or not the between-region analysis could reveal other significant differences, and particularly in the theta frequency band, because of the strict linkage between theta frequency generation and hippocampus. The results showed that the theta power band significantly increased on the frontal versus the temporo-parietal regions only in mild- and moderate-atrophy groups $(p<0.05)$. As a control analysis to test the specificity of these results for the theta frequency, we also checked differences in the alpha1 frequency band, where no significant difference was found during the single-region analysis. Also, no significant difference was found between regions in the alphal frequency band. As regards the other frequency bands, the significant results of the single-region analysis were confirmed by the between-region analysis. Other differences were not of interest for this study.

Finally, given the presence of major relative power changes in the high alpha frequency, changes of the EEG activity with respect to the hippocampal volume, as indexed by the individual alpha markers, were tested. The alpha markers (IAF and TF) were pooled, and their between-region changes were checked. The rationale for pooling IAF and TF is that they both are indices of the alpha frequency, and could give global information about the dominant frequency. So, it is of scientific interest to consider them together in order to better characterize the alpha frequency (Moretti et al., 2007). Table 3 shows means and standard errors for the alpha index (IAF + TF) with respect to the four subgroups of MCI subjects. Fig. 5 displays the second ANOVA analysis. The results show a significant group main effect $[F(3,84)=3.15) ; p<0.03]$. Duncan's post hoc analysis showed that the G4 group had the highest values for the alpha markers, when 
Table 2

Mean values \pm standard error for the alpha1/alpha3 ratio in the MCI subgroups on full scalp, frontal and temporo-parietal regions

\begin{tabular}{|c|c|c|c|c|}
\hline alpha1/alpha3 ratio & Group 1 & Group 2 & Group 3 & Group 4 \\
\hline Full scalp & $0.5( \pm 0.02)$ & $0.5( \pm 0.006)$ & $0.4( \pm 0.01)$ & $0.5( \pm 0.02)$ \\
\hline Frontal & $0.5( \pm 0.02)$ & $0.6( \pm 0.006)$ & $0.5( \pm 0.01)$ & $0.7( \pm 0.02)$ \\
\hline Temporo-parietal & $0.4( \pm 0.02)$ & $0.3( \pm 0.005)$ & $0.3( \pm 0.009)$ & $0.5( \pm 0.02)$ \\
\hline
\end{tabular}

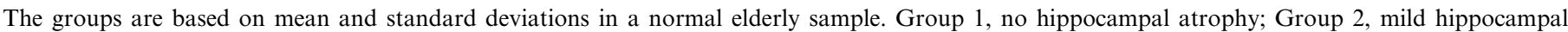
atrophy; Group 3, moderate hippocampal atrophy; Group 4, severe hippocampal atrophy.

compared to $\mathrm{G} 2$ and $\mathrm{G} 3$ ( $p<0.05 ; p<0.01$, respectively). As regards the G3 group, it showed the lowest value for the alpha marker, when compared to the G1 and G4 groups ( $p<0.05 ; p<0.008$, respectively). The $\mathrm{G} 2$ group showed a trend similar to that observed in the G3 group, with a significant decrease in the alpha markers in comparison with the $\mathrm{G} 4$ group $(p<0.05)$.

\section{Discussions}

\subsection{EEG and hippocampal atrophy}

The main result of this work is the finding that the relationship between hippocampal volume and EEG rhythmicity is not proportional to the hippocampal atrophy, as revealed by both the EEG relative band powers and the analysis of the individual alpha markers. In our analysis, such a pattern seems to emerge because discrete hippocampal volume differences (about $1 \mathrm{~cm}^{3}$ ) are analyzed. From a clinical point of view, our results could explain some discrepancies found in previous studies with respect to the

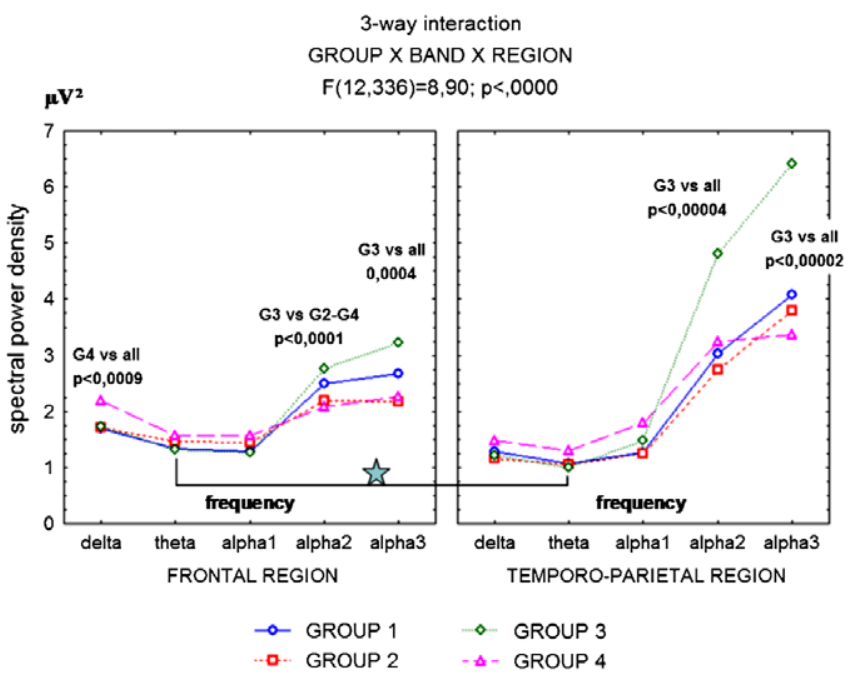

Fig. 4. Statistical ANOVA interaction among Group factors, and relative band powers (delta, theta, alpha1, alpha2, alpha3), and between regions (frontal and temporo-parietal). The groups are based on mean and standard deviations in a normal elderly sample. Group 1, no hippocampal atrophy; Group 2, mild hippocampal atrophy; Group 3, moderate hippocampal atrophy; Group 4, severe hippocampal atrophy. Post hoc results are indicated in the diagram. The blue star indicates significant differences in the theta power band. (For interpretation of the references to color in this figure legend, the reader is referred to the web version of this paper.)
MTL activation in MCI subjects. Moreover, they suggest that, when the clinical concept of MCI is dealt with, it could be useful to stage the disease with hippocampal volume measurements. Importantly, some patterns of EEG activity could be helpful in this regard.

\subsection{Theta frequency}

The analysis of the between-region differences shows that the relative theta power in the mild and moderate hippocampal-atrophy groups has higher values on frontal versus temporo-parietal regions in the same groups. It is therefore possible that, when relative band powers are compared between regions, the difference in the theta activity may emerge in specific groups. Thus, the comparison of the activity of different regions is a more sensible method to reveal new issues hidden in the 'within-region perspective'. This difference was specific for the theta frequency, in that it was not detected in the alphal band. Our results are in agreement with previous studies showing an increment of the theta rhythm in MCI subjects (Rossini et al., 2006; Prichep et al., 2006). From a functional point of view, the increase in the relative theta band power on the frontal regions is a sign of cortical activation (Sauseng et al., 2002), and particularly of an increase in the activity of hippocampal-medial prefrontal pathways (Tesche and Karhu, 2000; Apergis-Schoute et al., 2006; Vertes, 2006; Colom, 2006). Early studies showed an increase in a midline frontal theta band during cognitive performance (Klimesch, 1997, 1999; Dickerson et al., 2005; Dickerson, 2006; Hamalainen et al., 2006; Johnson, 2006), and the theta rhythm was proposed to be involved in the transfer of information between working memory and long-term memory systems (Sauseng et al., 2002). Moreover, an increase in the theta rhythm and a decrease in the delta rhythm were previously demonstrated after cholinergic stimulation (Nunez and Srinivasan, 2006). An increase in the theta rhythm was also found in vascular demented versus AD patients (Moretti et al., 2004). In this previous work, the authors discussed this finding as a major characteristic of the dementia secondary to vascular damage, rather than to degenerative impairment. However, this discrepancy is only apparent, since two types of theta rhythm exist, that is, a large, irregular, non-rhythmic activity and a rhythmic, slow activity connected with activation (Kramis et al., 1975; Gołebiewski et al., 2002). The concomitant finding of a decrease in the delta power (Gloor et al., 1977) in the moderate hippo- 
Table 3

Mean values \pm standard error for the individual alpha index (IAF + TF) in the MCI subgroups on full scalp, frontal and temporo-parietal regions

\begin{tabular}{llcl}
\hline Alpha index & Group 1 & Group 2 & Group 3 \\
\hline Full scalp & $15.5( \pm 0.2)$ & $15.1( \pm 0.04)$ & $15.3( \pm 0.09)$ \\
Frontal & $15.2( \pm 0.2)$ & $15( \pm 0.04)$ & $14.7( \pm 0.07)$ \\
Temporo-parietal & $15.4( \pm 0.2)$ & $15( \pm 0.04)$ & $15.1( \pm 0.08)$ \\
\hline
\end{tabular}

The groups are based on mean and standard deviations in a normal elderly sample. Group 1, no hippocampal atrophy; Group 2, mild hippocampal atrophy; Group 3, moderate hippocampal atrophy; Group 4, severe hippocampal atrophy.

campal-atrophy group, during the within-region analysis (and confirmed by the between-region analysis also in the mild-atrophy group) on the frontal area, could support the hypothesis of cortical activation based on the presence of theta rhythm. With respect to other studies, our results specify that the supposed compensatory activation is present when the hippocampal atrophy reaches a determined discrete range and, from a physiological point of view, finds expression in the 'native language' of the hippocampus, i.e., the theta rhythm.

\subsection{Alpha frequency}

\subsubsection{Relative power of the alpha rhythm and hippocampal atrophy}

As regards the relative alpha band power, all the withinregion analyses, namely the analyses of full scalp, frontal and temporo-parietal regions, show that the group with moderate hippocampal atrophy has the highest value for the alpha 2 and alpha 3 powers. The statistical difference with respect to other groups is always significant, except in the frontal region, where the group without hippocampal atrophy has values for the alpha 2 and alpha3 power bands that are very similar to those for the volume in the moderate-atrophy group. The analysis of the betweenregion differences confirms these results. The increase in the alpha power is largely accepted to be based on a state of hyperpolarization at thalamic level (Jones, 2002; Nicolelis and Fanselow, 2002; Klimesch et al., 2006). In the moderate hippocampal-atrophy group, the spreading of the

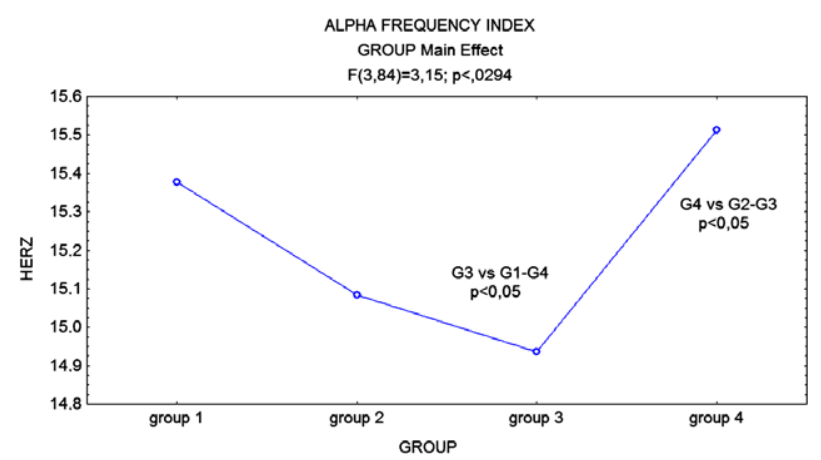

Fig. 5. Between-region statistical ANOVA main effect of Group for the pooled individual alpha markers ( $\mathrm{TF}$ and IAF). The groups are based on mean and standard deviations in a normal elderly sample. Group 1, no hippocampal atrophy; Group 2, mild hippocampal atrophy; Group 3, moderate hippocampal atrophy; Group 4, severe hippocampal atrophy. Post hoc results are indicated in the diagram. synchronization of the alpha2 and alpha3 bands on a diffuse network, including frontal and temporo-parietal regions, could be due to a progressive recruitment of different and larger cortical areas implying the involvement of wider corticothalamic re-entry loops, namely the loop of the frontal-midline thalamic nuclei (O'Donnell and Grace, 1995). Interestingly, in the group without hippocampal atrophy, a high value for the relative alpha 2 and alpha3 powers (that is similar to the value for the moderate hippocampal-atrophy group) is present only on the frontal regions. Given the normal value for the hippocampal volume in the group without atrophy, such synchronization in frontal regions, rather than from an activation of the corticothalamic re-entry loop, may result from the comparatively dense representation of cholinergic receptors and fibers in brainstem and proencefalic areas projecting to this region (Saykin and Wishart, 2003; Mesulam, 2004a).

Within the alpha band, only the relative alpha 2 and alpha3 band powers showed a tuning based on the hippocampal atrophy, whereas no change was found in the relative alphal power. It is now well known that the alpha frequency is not a unitary phenomenon (Klimesch, 1999). Different frequency bands show a very distinct type of reactivity. Lower alpha frequencies are related to general attention demands. Upper alpha frequencies show a clear relation to higher-order processing demands (Klimesch et al., 1994; Klimesch, 1999; Doppelmays et al., 2002; Ramcharan et al., 2005). So, the increase in the relative alpha 2 and alpha3 powers could be due to synchronization in associative cortical areas and/or higher-order thalamic nuclei, where cognitive processes take place.

The alphal rhythm is not influenced by the hippocampal atrophy. Previous literature showed clearly that a low alpha power is related to the cortical-basal cholinergic tone mainly provided by the forebrain efferent projections, especially from the nucleus basalis of Meynert (Holschneider et al., 1998; Sarter and Bruno, 1997, 1999, 2000). Therefore, our results confirm that the hippocampal atrophy is not related to a low alpha band power. Moreover, in the MCI cohort, the structural degeneration of the nucleus basalis is not yet severe (Mesulam et al., 2003). This could maintain the overall level of the slowest alpha band power across the MCI population, although functional modifications in other alpha bands may be present. The progressive course of the degenerative atrophy of the nucleus basalis, that is typical of $\mathrm{AD}$, is very likely to lead to a decrease in the slowest alpha band power (Moretti et al., 2004; Babiloni et al., 2006a). The different impact of the hippocampal 
atrophy on low alpha and high alpha bands is confirmed by the alpha1/alpha3 ratio among MCI groups, for the frontal region. Indeed, a significant increase in the alpha1/alpha3 ratio is present from the mild to the severe hippocampalatrophy groups, due to a decrease in the relative alpha3 power. Probably because of its complex structure and close connection with the hippocampus (Johnson, 2006), the frontal region is more sensitive than other regions. This could be very important from a clinical point of view, because the frontal alpha1/alpha3 ratio could be a reliable index of hippocampal atrophy and amnesic MCI. If confirmed, it could be used for differential diagnosis.

\subsubsection{Clinical relevance of alpha synchronization in MCI subjects}

From a behavioural point of view, the increase in the alpha power has been related to a period in which a change in the environment is expected (Nicolelis and Fanselow, 1999, 2002), or to an earlier phase of semantic encoding (Klopp et al., 2000; Mima et al., 2001; Klimesch et al., 2007). Recently, the 'inhibition hypothesis' has been proposed to explain the synchronization of the alpha rhythm (Klimesch et al., 2007). According to this hypothesis, alpha synchronization is involved in an active inhibition process. In particular, the top-down inhibitory control has been proposed to enhance the alpha power, as opposed to bottom-up processes in which the sensory stimulus must be actively processed. The increase in alpha activity is associated with an increase in the internal control of attention in situations where sensory information must not be processed (Von Stein et al., 2000; Cooper et al., 2003, 2006; Wolfe and Bell, 2003; Harris, 2005). As a consequence, alpha synchronization could inhibit the normal processing of sensory stimuli. These conclusions have to be taken with caution, because alpha synchronization was found on frontal regions far from sensory areas (Golob et al., 2007). However, it could not be excluded that the prevalence of a top-down inhibitory control mechanism enhances the alpha power in sensory areas. On the whole, the increase in the alpha power could suggest a general state of 'hyper-attention' in a particular stage of the disease, during which top-down internal processes predominate over the bottom-up phase, alter the attention mechanism and prevent a correct processing of sensory stimuli. Focused attention was found to be impaired in MCI patients, particularly when they had to benefit from a cue stimulus (Kemp and Kaada, 1975; Johannsen et al., 1999; Berardi et al., 2005; Levinoff et al., 2005; Tales et al., 2005a,b).

\subsubsection{Alpha frequency index: relationship with relative alpha power and hippocampal atrophy}

The difference in the alpha frequency index could support the finding of different phases in the course of the disease. Previous works (Klimesch, 1997, 1999; Moretti et al., 2004, 2007) showed that TF and IAF could provide information about the thalamo-cortical mechanism contributing to the generation of the alpha rhythm. In particular, the theta/alpha transition frequency (TF) is associated with the axonal conduction time, whereas the individual alpha frequency (IAF) is associated with cortico-thalamo-cortical excitatory or inhibitory mechanisms. Moreover, these indices give information other than relative spectral power. In fact, the low alpha frequency band (alpha1 and alpha2) is mainly related to thalamo-cortical synchronization and vigilance state, whereas the high alpha frequency band (alpha3) is mainly related to corticocortical synchronization and semantic function (Klimesch, 1997, 1999; Moretti et al., 2004, 2007). The pool of IAF and TF is considered to be a reliable index of the dominant frequency (Klimesch, 1997, 1999; Moretti et al., 2004, 2007). A recent work (Sarnthein and Jeanmonod, 2007) has convincingly demonstrated - through simultaneous recordings of local field potentials from thalamic nuclei, and of the EEG from the scalp - that a state of hyperpolarization in the thalamic nucleus induces a slowing of the EEG dominant frequency. The decrease in the values for the alpha frequency markers in mild and moderate hippocampal-atrophy groups suggests a greater hyperpolarization state of the thalamo-cortical pathways than in the no-hippocampal-atrophy group, probably due to the glutamatergic cortical excitatory activity on thalamic nuclei (Jones, 2002). At odds, in the group with severe hippocampal atrophy, our results show a decrease in relative power values, but the highest values for the alpha index. This could be due to induction of widespread depolarization throughout the brainstem ascending cholinergic projections, which mainly target the thalamus and are relatively spared, in comparison with the nucleus basalis cholinergic afference (Steriade and Deschenes, 1984; Selden et al., 1998). On the whole, a complex picture emerges in which thalamic synchronization leads to a decrease in the alpha index, and to an increase in the relative alpha power. On the contrary, thalamic desynchronization induces an increase in the alpha index, and a decrease in the relative alpha power. These phenomena (Figs. 6 and 7) are related to the hippocampal atrophy. The mild hippocampal-atrophy group shows an intermediate pattern, probably due to initial hippocampal and thalamo-cortical dysfunctions (Llinas et al., 1999; Mesulam et al., 2004b; Hamalainen et al., 2006; Klimesch et al., 2007).

\subsubsection{Alpha and theta rhythm interplays in MCI subjects: clinical significance and implications}

Taken together, our results show that, in a particular phase of the hippocampal degeneration in MCI, there is an increased activation of the hippocampus that triggers (or is associated with) a corticothalamic re-entry activity; which leads to the prevalence of a cortical top-down inhibitory control process, and generates a kind of 'hyperattentive state'. In the initial phase of this activity (i.e., in the mild-atrophy hippocampal stage), the increase in theta oscillations is not yet able to trigger a corticothalamic activity, which starts in the subsequent state (i.e., in the moderate-atrophy hippocampal stage). This particular state could be useful for maintaining a relatively spared 

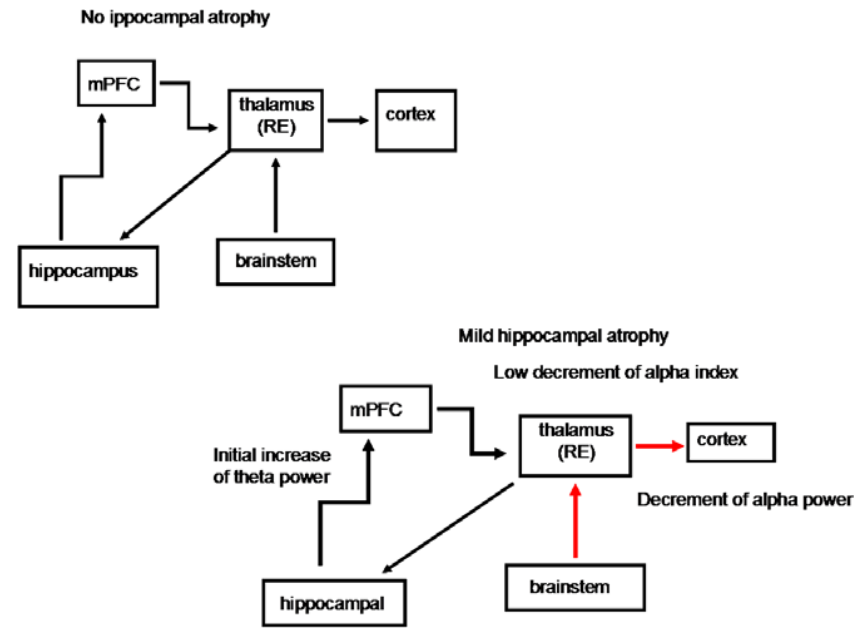

Fig. 6. Schematic diagrams of the possible structures involved in the thalamo-cortical arrhythmia in groups without hippocampal atrophy and with mild hippocampal atrophy. The EEG changes in the mild hippocampal-atrophy group are probably due to a prevalent depolarizing effect of the brainstem cholinergic system on the thalamus, because of initial neuronal loss in the cholinergic basal forebrain. On the other hand, the initial hippocampal atrophy gives rise to an increase in the theta activity, but it is not able to trigger thalamo-cortical synchronization activity (See the text for details). mPFC, medial prefrontal cortex; thalamus RE, nucleus reuniens of the thalamus. Black thick arrow, excitatory activity; blue arrow, synchronization effect; red arrow, desynchronization effect. (For interpretation of the references to color in this figure legend, the reader is referred to the web version of this paper.)

global cognitive performance, whereas it could fail when a detailed analysis of a sensory stimulus is required. This 'hyperattentive' state could represent the attempt to recollect memory and/or spatial traces from the hippocampus, and to combine them within associative areas connected with the hippocampus itself. The bioelectrical signature of this effort is represented by the interplay between theta and alpha rhythms (Sauseng et al., 2002). Our findings confirm previous literature. Indeed, an increased pattern of activation in hippocampus (Dickerson et al., 2005; Dickerson, 2006), as well as in posterior regions (Hamalainen et al., 2006), were previously described in MCI subjects during encoding tasks. In these studies, the MCI subjects also showed an increased fMRI response, in comparison with both normal control and AD subjects. Interestingly, this increased activation was related to a normal cognitive performance. Nonetheless, attention as well as visuo-spatial and memory deficits were described in MCI subjects (Miller, 1991; Levinoff et al., 2005; Tales et al., 2005a,b). It has been suggested that the exchange of information between working memory system and long-term system is reflected by the interplay between theta and alpha oscillations (Sauseng et al., 2002). The theta-driven upper alpha synchronization permits information recollection from the long-term storage, under the 'guide' of the short-term memory. Our results confirm that, once the hippocampal atrophy has reached a critical point, the theta-alpha interplay could become the default mode of the brain. This state is absent in other MCI subgroups. However, the increase in

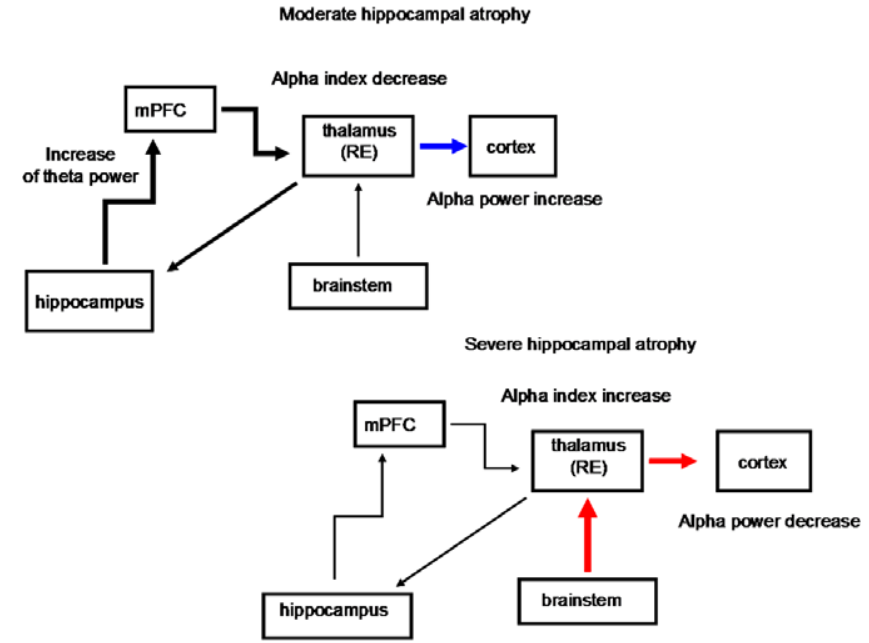

Fig. 7. Schematic diagrams of the possible structures involved in the thalamo-cortical arrhythmia in groups with moderate and severe hippocampal atrophy. The progressive hippocampal atrophy, as in the moderate hippocampal-atrophy group, triggers thalamo-cortical synchronization, with increase in the alpha power band. This is likely to happen because the return pathway from the cortex to the hippocampus is not direct, but it mainly relays to the midline and mediodorsal thalamic nuclei. The decrease in the values for the alpha frequency markers in the moderate hippocampal-atrophy group also suggests a greater hyperpolarization state of thalamo-cortical pathways. As the hippocampal atrophy progresses, like in the group with severe hippocampal atrophy, the thalamocortical activity is sustained not by cortical activation, but by the prevailing cholinergic desynchronizing activity of the brainstem, with a decrease in the relative alpha power but the highest values for the alpha indices (See text for details). mPFC, medial prefrontal cortex; thalamus $\mathrm{RE}$, nucleus reuniens of the thalamus. Black thick arrow, excitatory activity; blue arrow, synchronization effect; red arrow, desynchronization effect. (For interpretation of the references to color in this figure legend, the reader is referred to the web version of this paper.)

the theta activity on the frontal region, such as has been observed also in the group with mild hippocampal atrophy, shows an initial phase of the process that fully develops in a subsequent stage. On the whole, it could be argued that, in different phases, bottom-up processes predominate over or are in equilibrium with - the top-down activity, with alternating pattern of EEG rhythmicity.

\subsection{The role of age}

In our study, the results show that age factor differed significantly among groups. So, the influence of age on results and, above all, on pathological neurodegenerative mechanisms was indeed a problem. Increased recruitment of frontal cortical areas was detected in elderly healthy subjects (Cabeza et al., 2004; Logan et al., 2002; Park et al., 2003) during memory tasks. Moreover, age-related increase in the activation of frontal cortices and hippocampus, and decreased activity in fusiform gyrus have recently been detected in normal elderly subjects (Grady et al., 2006). This suggests that MCI subjects may present both agingrelated changes and alterations related to AD-type pathology (Sarter and Bruno, 2004; Rossini et al., 2007). 
However, a large body of evidence demonstrates that, during memory tasks, in MCI subjects a greater cortical activation occurs than in normal elderly subjects (Dickerson et al., 2005). In a recent study, auditory cortical activity not only has been shown to increase in normal elderly subjects, but it increases even more in MCI subjects whose impairment turns into dementia (Golob et al., 2007). Age-related mechanisms have been related to a low-frequency shift in the EEG spectrum, and to a reduction of complexity of large-scale brain systems (Wink et al., 2006). Our results confirm that MCI could show an agerelated pattern, but not in all phases of the disease. These results were further confirmed when a subsidiary analysis was conducted in age-matched groups. On the whole, in the present study some previous clinical outcomes were confirmed, and it was pointed out that taking into account which stage the hippocampal atrophy is at could be helpful in understanding some clinical manifestations of the MCI condition.

\subsubsection{Differences between EEG hallmarks in hippocampal damage and CVD: tools for differential diagnosis?}

The differences in pathophysiological mechanisms, and related EEG changes, between hippocampal atrophy and CVD are an interesting clinical issue. A recent study (Moretti et al., 2007) has found main EEG hallmarks of CVD in MCI subjects, as follows: (1) EEG changes are proportional to CVD; (2) the theta power band is not influenced by CVD; (3) the alpha3 band is not influenced by CVD; (4) the alphal band is influenced by CVD; (5) an increase in the theta/alpha1 ratio, and a decrease in the alpha2/ alpha3 ratio, are indicative of CVD. In this study of the hippocampal atrophy, results are very different: (1) EEG changes are not proportional to the hippocampal atrophy; (2) the frontal theta band is influenced by the hippocampal atrophy (2) the alpha3 band is strongly influenced by the hippocampal atrophy; (3) the alpha1 band is not influenced by the hippocampal atrophy; (4) the increase in the alpha1/ alpha3 power band ratio on the frontal region is the sole significant and indicative ratio for the hippocampal atrophy. If confirmed, these results could be helpful in differential diagnosis, or in understanding the dominant pathological mechanism underlying the mixed forms of MCI.

\section{Conclusions}

EEG-rhythm changes are not proportional to the hippocampal atrophy in MCI subjects. EEG measurements and hippocampal atrophy markers could be helpful in detecting different stages of the clinical picture of MCI. Finally, EEG changes associated with hippocampal atrophy are very different from those associated with CVD.

\section{References}

Albert M, Smith LA, Scherr PA, Taylor JO, Evans DA, Funkenstein HH. Use of brief cognitive tests to identify individuals in the community with clinically diagnosed Alzheimer's disease. Int J Neurosci 1991;57(3-4):167-78.

Amodio P, Wenin H, Del Piccolo F, Mapelli D, Montagnese S, Pellegrini A, et al. Variability of trial making test, symbol digit test and line trait test in normal people. A normative study taking into account agedependent decline and sociobiological variables. Aging Clin Exp Res 2002;14:117-31.

Apergis-Schoute J, Pinto A, Parè D. Ultrastructural organization of medial prefrontal inputs to the rhinal cortices. Eur J Neurosci 2006:24-144.

Apostolova LG, Dinov ID, Dutton RA, Kiralee MH, Toga AW, Cummings $\mathrm{Jl}$, et al. 3D comparison of hippocampal atrophy in amnestic mild cognitive impairment and Alzheimer's disease. Brain 2006:1-7.

Arnold SE, Hyman BT, Flory J, Damasco AR, Van Hoesen GW. The topographical and neuroanatomical distribution od neurofibrillarity tangles and neuritic plaques in the cerebral cortex of patients with Alzheimer's disease. Cereb Cortex 1991;1:103-16.

Babiloni C, Babiloni F, Carducci F, Cincotti F, Del Percio C, De Pino G, et al. Movement-related electroencephalographic reactivity in Alzheimer disease. Neuroimage 2000;12(2):139-46.

Babiloni C, Binetti G, Cassetta E, Dal Forno G, Del Percio C, Ferreri F, et al. Sources of cortical rhythms change as a function of cognitive impairment in pathological aging: a multi-centric study. Clin Neurophysiol 2006a;117(2):252-68.

Babiloni C, Frisoni G, Steriade M, Bresciani L, Binetti G, Del Percio $\mathrm{C}$, et al. Frontal white matter volume and delta EEG sources negatively correlate in awake subjects with mild cognitive impairment and Alzheimer's disease. Clin Neurophysiol 2006b;117:1113-29.

Basso A, Capitani E, Laiacona M. Raven's coloured progressive matrices: normative values on 305 adult normal controls. Funct Neurol 1987;2:189-94.

Bennett DA, Schneider JA, Bienais JL, Evans DA, Wilson RS. Mild cognitive impairment is related to Alzheimer disease pathology and cerebral infarctions. Neurology 2004;23:325-35.

Bennys K, Rondouin G, Vergnes C, Touchon J. Diagnostic value of quantitative EEG in Alzheimer's disease. Neurophysiol Clin 2001;31:153-60.

Berardi AM, Parasuraman R, Haxby JV. Sustained attention in mild Alzheimer's disease. Dev Neuropsychol 2005;58:507-37.

Bobinski M, Wegiel J, Wisniewski HM, Tarnawski M, Reisberg B, Mlozidc B, et al. Atrophy of hippocampal formation subdivisions correlates with stage and duration of Alzheimer's disease. Dementia 1995;6:205-10.

Cabeza R, Daselaar SM, Dolcos F, Prince SE, Budde M, Nyberg L. Taskindependent and task specific age effects on brain activity during working memory, visual attention and episodic retrieval. Cereb Cortex 2004;14:364-75.

Caffarra P, Vezzadini G, Dieci F, Zonato F, Venneri A. Rey-Osterrieth complex figure: normative values in an Italian population sample. Neurol Sci 2002;22:437-43.

Callen Dj, Black SE, Gao F, Caldwell CB, Szalai JP. Beyond the hippocampus: MRI volumetry confirms widespread limbic atrophy in AD. Neurology 2001;57:1669-74.

Carlesimo GA, Caltagirone C, Gainotti G. The Mental Deterioration Battery: normative data, diagnostic reliability and qualitative analyses of cognitive impairment. The Group for the Standardization of the Mental Deterioration Battery. Eur Neurol 1996;36:378-84.

Collins DL, Neelin P, Peters TM, Evans AC. Automatic 3D intersubject registration of MR volumetric data in standardized Talairach space. J Comput Assist Tomogr 1994;18:192-205.

Colom LV. Septal networks: relevance to theta rhythm, epilepsy and Alzheimer's disease. J Neurochem 2006;96:609-23.

Cooper NR, Croft RJ, Dominey SJJ, Burgess AP, Gruzelier JH. Paradox lost? Exploring the role of alpha oscillations during externally vs. internally directed attention and the implications for idling and inhibition hypotheses. Int J PsychoPhysiol 2003;47:65-74. 
Cooper NR, Burgess AP, Croft RJ, Gruzelier JH. Investigating evoked and induced electroencephalogram activity in task-related alpha power increase during an internally directed attention task. Neuroreport 2006;17:205-8.

DeKosky ST, Ikonomovic MD, Styren SD, Beckett L, Wisniewski S, Bennett DA, et al. Upregulation of choline acetyltransferase activity in hippocampus and frontal cortex of elderly subjects with mild cognitive impairment. Ann Neurol 2002;51:145-55.

Della Maggiore V, Chau W, Peres-Neto PR, McIntosh AR. An empirical comparison of SPM preprocessing parameters to the analysis of fMRI data. Neuroimage 2002;17:19-28.

Destexhe A, Sejnowski TJ. Synchronized oscillations in thalamic networks: insight from modeling studies. In: Steriade M, Jones EG, McCormick DA, editors. Thalamus. Amsterdam: Elsevier; 1996.

Devanand DP, Folz M, Gorlyn M, Moeller JR, Stern J. Questionable dementia: clinical course and predictors of outcome. J Am Geriatr Soc 1997;45:321-8.

Dickerson BC, Salat DH, Bates JF, Atiya M, Kiliiany RJ, Greve DN, et al. Medial temporal lobe function and structure in mild cognitive impairment. Ann Neurol 2004;56:27-35.

Dickerson BC, Salat DH, Greve DN, Chua EF, Rand-Giovannetti E, Rentz DM, et al. Increased hippocampal activation in mild cognitive impairment compared to normal aging and AD. Neurology 2005;65:404-11.

Dickerson BC. Functional magnetic resonance imaging of cholinergic modulation in mild cognitive impairment. Curr Opin Psychiatry 2006;19:299-306.

Doppelmays M, Klimesch W, Stadler W, Pollhuber D, Heine C. EEG alpha power and intelligence. Intelligence 2002;30:289-302.

Du AT, Schuff N, Amend D, Laasko MP, Hsu YY, Jagust WJ, et al. magnetic resonance imaging of the enthorinal cortex and hippocampus in mild cognitive impairment and Alzheimer's disease. J Neurol Neurosurg Psychiatry 2001;71:441-7.

Elul R. The genesis of EEG. Int Rev Neurobiol 1972;15:227-72.

Ferreri F, Pauri F, Pasqualetti P, Fini R, Dal Forno G, Rossini PM. Motor cortex excitability in Alzheimer's disease: a transcranial magnetic stimulation study. Ann Neurol 2003;53(1):102-8.

Fischer P, Jungwirth S, Zehetmayer S, Weissgram S, Hoenigschnabl S, Gelpi E, et al. Conversion from subtypes of mild cognitive impairment to Alzheimer dementia. Neurology 2007;68:288-91.

Flicker CS, Ferris H, Reisberg B. Mild cognitive impairment in the elderly: predictors of dementia. Neurology 1991;41:1006-9.

Folstein MF, Folstein SE, McHugh PR. 'Mini mental state': a practical method for grading the cognitive state of patients for clinician. J Psychiatry Res 1975;12:189-98.

Frisoni GB, Testa C, Zorzan A, Sabattoli F, Beltramello A, Soininen H, et al. Detection of grey matter loss in mild Alzheimer's disease with voxel based morphometry. J Neurol Neurosurg Psychiatry 2002;73(6):657-64.

Gauthier S, Reisberg B, Zaudig M, Petersen RC, Ritchie K, Broich K, et al. International Psychogeriatric Association Expert Conference on mild cognitive impairment. Mild cognitive impairment. Lancet 2006:1262-70.

Geroldi C, Rossi R, Calvagna C, Testa C, Bresciani L, Binetti G, et al. Medial temporal atrophy but not memory deficit predicts progression to dementia in patients with mild cognitive impairment. J Neurol Neurosurg Psychiatry 2006;77:1219-22.

Gloor P, Ball G, Schaul N. Brain lesions that produce delta waves in the EEG. Neurology 1977;27(4):326-33.

Gold G, Bouras C, Kovari E, Canito A, Glaria BG, Malky A, et al. Clinical validità of Braak neuropathological staging in the oldest-old. Acta Neuropathol 2000;99:579-82.

Gołebiewski H, Eckersdorf B, Konopacki J. Septal cholinergic mediation of hippocampal theta in the cat. Brain Res Bull 2002;58(3):323-35.

Golob EJ, Irimajiri R, Starr A. Auditory cortical activity in amnestic mild cognitive impairment: relationship to subtype and conversion to dementia. Brain 2007;130:740-52.
Grady CL, Springer MV, Hongwanishkul D, McIntosh AR, Winocur G. Age-related changes in brain activity across the adult lifespan. J Cogn Neurosci 2006;18:227-41.

Gueguen B, Derouesne C, Bourdel MC, Guillou S, Landre E, Gaches J, et al. Apport de l'EEG quantifiee au diagnostic de demence de type Alzheimer. Neurophysiol Clin 1991;21:357-71.

Hamalainen A, Pihlaimaki M, Tanila H, Hanninen T, Niskanen E, Tervo $\mathrm{S}$, et al. Increased fMRI responses during encoding in mild cognitive impairment. Neurobiol Aging 2006, Available from: doi:10.1016/ j.neurobiolaging.2006.08.008.

Harris JB. Differential conditioning of alpha amplitude: a fresh look at an old phenomenon. Clin Neurophysiol 2005;116:1433-43.

Holschneider DP, Leuchter AF, Scremin OU, Treiman DM, Walton NW. Effects of cholinergic deafferentation and NGF on brain electrical coherence. Brain Res Bull 1998;45:531-41.

Huang C, Wahlund LO, Dierks T, Julin P, Winblad B, Jelic V. Discrimination of Alzheimer's disease and mild cognitive impairment by equivalent EEG sources: a cross-sectional and longitudinal study. Clin Neurophysiol 2000;11:1961-7.

Hughes CP, Berg L, Danziger WL, Cohen LA, Martin RL. A new clinical rating scale for the staging of dementia. $\mathrm{Br} \mathrm{J}$ Psychiatry 1982;140:1225-30.

Jelic V, Shigeta M, Julin P. Quantitative electroencephalography power and coherence in Alzheimer's disease and mild cognitive impairment. Dementia 1996;7:314-23.

Jelic V, Johansson SE, Almkvist O, Shigeta M, Julin P, Nordberg A, et al. Quantitative electroencephalography in mild cognitive impairment: longitudinal changes and possible prediction of Alzheimer's disease. Neurobiol Aging 2000;21(4):533-40.

Johannsen P, Jacobsen J, Bruhn P, Gjedde A. Cortical responses to sustained and divided attention in Alzheimer's disease. Neuroimage 1999;10:269-81.

Johnson JD. The conversational brain: fronto-hippocampal interaction and disconnection. Med Hypotheses 2006;67:759-64.

Jones EG. Thalamic circuitry and thalamocertical synchrony. Phil Trans R Soc Land B 2002;357:1659-73.

Kemp IR, Kaada BR. The relation of hippocampao theta activity to arousal, attentive behavior and somato-motor movements in unrestrained cats. Brain Res 1975;95:323-434.

Klimesch W, Schimke H, Schwaiger J. Episodic and semantic memory: an analysis in the EEG theta and alpha band. Electroencephalogr Clin Neurophysiol 1994;91(6):428-41.

Klimesch W. EEG-alpha rhythms and memory processes. Int J Psychophysiol 1997;26:319-40.

Klimesch W. EEG alpha and theta oscillations reflect cognitive and memory performance: a review and analysis. Brain Res Rev 1999;29:169-95.

Klimesch W, Sauseng P, Hanslmayr S. EEG alpha oscillations: the inhibition timing hypothesis. Brain Res Rev 2007;53:63-88.

Klopp J, Marinkovic K, Chauvel P, Nenov V, Halgren E. Early widespread cortical distribution of coherent fusiform face selective activity. Hum Brain Mapp 2000;11:286-93.

Koenig T, Prichep L, Dierks T, Hubl D, Wahlund LO, John ER, et al. Decreased EEG synchronization in Alzheimer's disease and mild cognitive impairment. Neurobiol Aging 2005;26(2): 165-71.

Kramis R, Vanderwolf $\mathrm{CH}$, Bland $\mathrm{BH}$. Two types of hippocampal rhythmical slow activity in both rabbit and the rat: relations to behavior and effects of atropine, diethyl ether, urethane, and pentobarbital. Exp Neurol 1975;49:58-85.

Lavenex P, Amaral DG. Hippocampal-neocortical interaction: a hierarchy of associativity. Hippocampus 2000;10:420-30.

Lawton MP, Brodie EM. Assessment of older people: self maintaining and instrumental activity of daily living. J Gerontol 1969;9:179-86.

Leuchter AF, Cook IA, Newton TF, Dunkin J, Walter DO, RosenbergThompson S, et al. Regional differences in brain electrical activity in dementia: use of spectral power and spectral ratio measures. Electroencephalogr Clin Neurophysiol 1993;87:385-93. 
Levinoff EJ, Saumier D, Chertkow H. Focused attention deficits in patients with Alzheimer's disease and mild cognitive impairment. Brain Cogn 2005;57:127-30.

Llinas RR, Ribary U, Jeanmonod D, Kronberg E, Mitra PP. Thalamocortical dysrhythmia: a neurological and neuropsychiatric syndrome characterized by magnetoencephalography. Proc Natl Acad Sci USA 1999;96(26):15222-7.

Logan JM, Sanders AL, Snyder AZ, Morris JC, Buckner RL. Underrecruitment and non-selective recruitment: dissociable neural mechanisms associated with aging. Neuron 2002;33:827-40.

Lopes da Silva FH, van Rotterdam A, Barts P, van Heusden E, Burr W. Models of neuronal populations: the basic mechanism of rhythmicity. In: Corner MA, Swaab DF, editors. Perspectives of brain research. Progress in brain research 1976; vol. 45. Amsterdam: Elsevier; 1976. p. 281-308.

Lopes da Silva FH, Mooibroek J, van Rotterdam A. Relative contribution of intracortical and thalamo-cortical process in the generation of alpha rhythms revealed by partial coherence analysis. Electroencephalogr Clin Neurophysiol 1980;50:449-56.

Machulda MM, Ward HA, Borowski B, Gunter JL, Cha RH, O'Brien Pc, et al. Comparison od memory fMRI response among normal, MCI, and Alzheimer's patients. Neurology 2003;61:500-6.

Maurer K, Dierks T. Functional imaging procedures in dementias: mapping of EEG and evoked potentials. Acta Neurol Scand 1992;139:40-6.

Mesulam MM, Siddique T, Cohen B. Cholinergic denervation in a pure multi-infarct state: observation on CADASIL. Neurology 2003;60:1183-5.

Mesulam MM. The cholinergic innervation of the human cerebral cortex. Prog Brain Res 2004a;145:67-78.

Mesulam M, Shaw P, Malsh D, Weintraub S. Cholinergic nucleus basalis tauopathy emerges early in the aging-MCI-AD continuum. Ann Neurol 2004b;55:815-28.

Miller R. Cortico-hippocampal interplay and the representation of contexts. Berlin: Springer-Verlag; 1991, 83-85.

Mima T, Oluwatimilehin T, Hiroak T, Hallet M. Transient interhemispheric neural synchrony correlates with object recognition. J Neurosci 2001;21:3942-8.

Moretti DV, Babiloni C, Binetti G, Cassetta E, Dal Forno G, Ferreri F, et al. Individual analysis of EEG frequency and band power in mild Alzheimer's disease. Clin Neurophysiol 2004;115:299-308.

Moretti DV, Miniussi C, Frisoni GB, Zanetti O, Binetti G, Geroldi C, et al. Vascular damage and EEG markers in subjects with mild cognitive impairment. Clin Neurophysiol 2007;118(8):1866-76.

Nicolelis MAL, Fanselow EE. Behavioral modulation of tactile responses in the rat somatosensory system. J Neurosci 1999;19(17):7603-16.

Nicolelis MAL, Fanselow EE. Dynamic shifting in thalamocortical process during different behavioral states. R Soc 2002;357:1753-8.

Novelli G, Papagno C, Capitani E, Laiacona M, Vallar G, Cappa SF. Tre test clinici di ricerca e produzione lessicale. Taratura su soggetti normali. Archivio di Psicologia, Neurologia e Psichiatria 1986;4:477-506.

Nunez PL, Wingeier BM, Silberstein RB. Spatial-temporal structures of human alpha rhythms: theory, microcurrent sources, multiscale measurements, and global binding of local networks. Hum Brain Mapp 2001;13:125-64.

Nunez PL, Srinivasan R. A theoretical basis for standing and traveling brain waves. Clin Neurophysiol 2006;117(11):2425-35.

O’Donnell P, Grace AA. Synaptic interactions among excitatory afferents to nucleus accumbens neurons: hippocampal gating of prefrontal cortical input. J Neurosci 1995;15:3622-39.

Pariente J, Cole S, Henson R, Clare L, Kennedy A, Rossor M, et al. Alzheimer's patients engage an alternative network during a memory task. Ann Neurol 2005;59:870-9.

Park DC, Welsh RC, Marshuetz C, Gutchess AH, Mikels J, Polk TA, et al. Working memory for complexes scenes: age differences in frontal and hippocampal activations. J Cogn Neurosci 2003;15:1122-34.
Pennanen C, Testa C, Laasko MP, Hallikainen M, Helkala EL, Hanninen $\mathrm{T}$, et al. A voxel based morphometry study on mild cognitive impairment. J Neurol Neurosurg Psychiatry 2005;76:11-4.

Petersen RC, Smith GE, Ivnik RJ, Tangalos EG, Schaid SN, Thibodeau $\mathrm{SN}$, et al. Apolipoprotein E status as a predictor of the development of Alzheimer's disease in memory impaired individuals. J Am Med Assoc 1995;273:1274-8.

Petersen RC, Smith GE, Waring SC, Ivnik RJ, Kokmen E, Tangelos EG. Aging, memory, and mild cognitive impairment. Int Psychogeriatr 1997;9(Suppl. 1):65-9.

Petersen RC. Mild cognitive impairment: transition between aging and Alzheimer's disease. Neurologia 2000;15(3):93-101.

Petersen RC, Doody R, Kurz A, Mohs RC, Morris JC, Rabins PV, et al. Current concepts in mild cognitive impairment. Arch Neurol 2001;58(12):1985-92.

Pfurtscheller G, Lopes da Silva F. Event-related EEG/MEG synchronization and desynchronization: basic principles. Clin Neurophysiol 1999;110:1842-57.

Portet F, Ousset PJ, Visser PJ, Frisoni GB, Nobili F, Scheltens Ph, et al. and the MCI Working Group of the European Consortium on Alzheimer's Disease (EADC). Mild cognitive impairment (MCI) in medical practice: a critical review of the concept and new diagnostic procedure. Report of the MCI Working Group of the European Consortium on Alzheimer's Disease. J Neurol Neurosurg Psychiatry 2006;77:714-718.

Pruessner JC, Li LM, Serles W, Pruessner M, Collins DL, Kabani N, et al. Volumetry of hippocampus and amygdala with high-resolution MRI and three-dimensional analysis software: minimizing the discrepancies between laboratories. Cereb Cortex 2000;10:433-42.

Price JL, Morris JC. Tangles and plaques in nondemented aging and preclinical Alzheimer's disease. Ann Neurol 1999;45:358-68.

Prichep LS, John ER, Ferris SH, Rausch L, Fang Z, Cancro R, et al. Prediction of longitudinal cognitive decline in normal elderly with subjective complaints using electrophysiological imaging. Neurobiol Aging 2006;27:471-81.

Radloff LS. The CES-D scale: a self-report depression scale for research in the general population. Appl Psychol Measure 1977;1:385-401.

Ramcharan EJ, Gnadt JW, Sherman SM. Higher-order thalamic relays burst more than first-order relays. PNAS 2005;102:12236-41.

Rosen WG, Terry RD, Fuld PA, Katzman R, Peck A. Pathological verification of ischemic score in differentiation of dementias. Ann Neurol 1980;7(5):486-8.

Rossini PM, Del Percio C, Pasqualetti P, Cassetta E, Binetti G, Dal Forno $\mathrm{G}$, et al. Conversion from mild cognitive impairment to Alzheimer's disease is predicted by sources and coherence of brain electroencephalography rhythms. Neuroscience 2006;143:793-803.

Rossini PM, Rossi S, Babiloni C, Polich J. Clinical neurophysiology of aging brain: From normal aging to neurodegeneration. Prog Neurobiol 2007. doi:10.1016/i.pneurobio.2007.07.010.

Saykin AJ, Wishart HA. Mild cognitive impairment: conceptual issues and structural and functional brain correlates. Semin Clin Neuropsychiatry 2003;8(1):12-30, Review.

Sarnthein J, Jeanmonod D. High thalamo-cortical theta coherence in patients with Parkinson's disease. J Neurosci 2007;27:124-31.

Sarter M, Bruno JP. Cognitive functions of cortical cholinergic: toward a unifying hypothesis. Brain Res Rev 1997;23:329-43.

Sarter M, Bruno JP. Abnormal regulation of corticopetal cholinergic neurons and impaired information processing in neuropsychiatric disorders. Trends Neurosci 1999;22:67-74.

Sarter M, Bruno JP. Cortical cholinergic inputs mediating arousal, attentional processing and dreaming: differential afferent regulation of the basal forebrain by telencephalic and brainstem afferents. Neuroscience 2000;95:933-52.

Sarter M, Bruno JP. Developmental origin of the age-related decline in cortical cholinergic function and associated cognitive abilities. Neurobiol Aging 2004;25:1127-39.

Sauseng P, Klimeschi W, Gruber W, Doppelmayr M, Stadler W, Schabus M. The interplay between theta and alpha oscillations in the human 
electroencephalogram reflects the transfer of information between memory systems. Neurosci Lett 2002;324:121-4.

Schonheit B, Zarski R, Ohm TG. Spatial and temporal relationships between plaques and tangles in Alzheimer pathology. Neurobiol Aging 2004;25:697-711.

Schreiter-Gasser U, Gasser Th, Ziegler P. Quantitative EEG-analysis in early onset alzheimer's disease: a controlled study. Electroencephalogr Clin Neurophysiol 1993;86:15-22.

Selden NR, Gitelman DR, Salamon-Nurayama N, Parrish TB, Mesulam MM. Trajectories of cholinergic pathways within the cerebral hemispheres of human brain. Brain 1998;121:2248-57.

Shulman KI. Clock-drawing: is it the ideal cognitive screening test? Int J Geriatr Psychiatry 2000;15:548-61.

Singer W. Synchronization of cortical activity and its putative role in information processing and learning. Annu Rev Physiol 1993;55:349-74.

Spinnler H, Tognoni G. Standardizzazione e taratura italiana di test neuropsicologici. Ital J Neurol Sci 1987;6(Suppl. 8):1-120.

Steriade M, Deschenes M. The thalamus as a neuronal oscillator. Brain Res Rev 1984;8:1-63.

Steriade M, Llinas RR. The functional states of the thalamus and the associated neuronal interplay. Physiol Rev 1988;68:649-742.

Suffczynski P, Stilian K, Pfurtscheller G, Lopes da Silva FH. Computational model of thalamo-cortical networks: dynamical control of alpha rhythms in relation to focal attention. Int J Psychophysiol 2001;43:25-40.

Tales A, Haworth J, Nelson S, Snowden RJ, Wilcock G. Abnormal visual search in mild cognitive impairment and Alzheimer's disease. Neurocase 2005a;11:80-4.

Tales A, Snowden RJ, Haworth J, Wilcock G. Abnormal spatial and nonspatial cueing effects in mild cognitive impairment and Alzheimer's disease. Neurocase 2005b;11(1):85-92.
Tapiola T, Pennanen C, Tapiola M, Tervo S, Kivipelto, Hanninen T, et al. MRI of hippocampus and enthorinal cortex in mild cognitive impairment: a follow-up study. Neurobiol Aging 2006, Available from: doi:10.1016/j.neurobiolaging.2006.09.007.

Tesche CD, Karhu J. Theta oscillation index human hippocampal activation during a working memory task. Proc Natl Acad Sci USA 2000;97:919-24.

Vertes RP. Interactions among the medial prefrontal cortex, hippocampus and midline thalamus in emotional and cognitive processing in the rat. Neuroscience 2006;142:1-20.

Von Stein A, Chiang C, Konig P. Top-down processing mediated by interareal synchronization. PNAS USA 2000;97:14748-53.

Wahlund LO, Barkhof F, Fazekas F, Bronge L, Augustin M, Sjögren M, et al. A new rating scale for age-related white matter changes applicable to MRI and CT. Stroke 2001;32:1318-22.

Wahlund LO, Pilhstrand E, Johnagen ME. Mild cognitive impairment: experience from a memory clinic. Acta Neurol Scand Suppl 2003;179:21-4.

Wink AM, Bernard F, Salvador, Bullmore E, Suckling J. Age and cholinergic effects on hemodynamics and functional coherence of human hippocampus. Neurobiol Aging 2006;27:1395-404.

Wolfe CD, Bell MA. Working memory and inhibitory control in early childhood: contributions from physiology, temperament, and language. Dev Psychobiol 2003;44:68-83.

Zappoli R, Versari A, Paganini M, Arnetoli G, Muscas GC, Gangemi $\mathrm{PF}$, et al. Brain electrical activity (quantitative EEG and bitmapping neurocognitive CNV components), psychometrics and clinical findings in presenile subjects with initial mild cognitive decline or probable Alzheimer-type dementia. Ital J Neurol Sci 1995;16(6):341-76. 